\title{
Production of Haploid Plant of 'Banpeiyu' Pummelo [Citrus maxima (Burm.) Merr.] by Pollination with Soft X-Ray-Irradiated Pollen
}

\author{
Masaki Yahata $^{1 * *}$, Kiichi Yasuda ${ }^{1}$, Kohji Nagasawa ${ }^{2}$, Seiichi Harusaki ${ }^{2}$, Haruki Komatsu ${ }^{2}$ \\ and Hisato Kunitake ${ }^{1 *}$
}

${ }^{1}$ Faculty of Agriculture, University of Miyazaki, Miyazaki 889-2192, Japan

${ }^{2}$ School of Agriculture, Tokai University, Kumamoto 869-1404, Japan

To induce haploid plants in Citrus maxima (Burm.) Merr. 'Banpeiyu', we evaluated the effect of pollination with soft X-ray-irradiated pollen on fruit set and seed development, and carried out ovule culture. When 'Banpeiyu' pummelo pistils were pollinated with X-ray-irradiated pollen of ' $F$ ukuhara' sweet orange $[C$. sinensis $(\mathrm{L}$.) Osbeck], the exposure doses affected the fruit set. The number of seeds per fruit was also affected by the exposure dose, and tended to decrease as the dose increased; however, all developed seeds obtained from these crosses were diploid. In the ovule culture of 'Banpeiyu' pummelo, six embryoids shown haploidy were obtained in all treatments. One haploid plantlet with 9 chromosomes was regenerated from an embryoid in a culture of ovules established 40 days after pollination with 400 Gray (Gy)-irradiated pollen of 'Tosa-buntan' pummelo (C. maxima). This haploid was suggested to be derived from 'Banpeiyu' pummelo by random amplified polymorphic DNA (RAPD) and cleaved amplified polymorphic sequence (CAPS) analysis.

Key Words: chromosome observation, cleaved amplified polymorphic sequence (CAPS), flow cytometry, ovule culture, random amplified polymorphic DNA (RAPD).

\section{Introduction}

Haploids have significant potential in Citrus breeding, because homozygous plants, which are very important for genetic analysis and breeding, are easily obtained by doubling their chromosomes. Through the fusion of haploid protoplasts, new forms of interspecific and intergeneric hybrids can be obtained (Grosser et al., 2000). Furthermore, gene transfer or mutagenesis of haploids, followed by chromosome doubling, would enable recessive genes to be expressed. In Citrus, haploid seedlings were first obtained by the application of $\gamma$-rays in natsudaidai (C. natsudaidai Hayata) (Karasawa, 1971). Esen and Soost (1971) described a haploid embryo obtained from an immature seed of clementine mandarin (C.clementina hort. ex Tanaka) $\times$ 'Pearl' tangelo cross. Since then, haploids have been produced by anther culture (Germanà and Chiancone, 2003; Germanà et al., 1994; Hidaka et al., 1979) and interploid

Received; June 24, 2009. Accepted; January 15, 2010.

* Corresponding author (E-mail: hkuni@cc.miyazaki-u.ac.jp).

** Present address: Faculty of Agriculture, Shizuoka University, Shizuoka 422-8529, Japan. hybridization (Germanà and Chiancone, 2001; Oiyama and Kobayashi, 1993; Toolapong et al., 1996); however, these alternative methods have not been effective, and so it was difficult to carry out genetic analysis and breeding using haploids.

Recent biological studies of various plants suggest that parthenogenesis induced by the pollination of inactivated pollen with or without a pseudo-fertilized ovule culture might represent an alternative technique for the production of haploid plants in plant species in which anther culture is inefficient. Sauton and Dumas (1987) first succeeded in producing haploid plants in several cultivars of melon (Cucumis melo L.) using the pseudo-fertilized ovule culture technique. They cultured immature ovules after fertilization with pollen irradiated with 300 Gy of $\gamma$-rays from a cobalt 60 source. Katoh et al. (1993) also reported high-frequency haploid production in melon by the same pseudo-fertilized ovule culture (maximum $3.4 \%$ per examined ovule), although the frequency varied with the genotype. In fruit trees, haploid plants induced by irradiated pollen have been reported for apple (Malus domestica Borkh.) (Zhang and Lespinasse, 1991), pear (Pyrus communis L.) (Bouvier et al., 1993), and kiwifruit [Actinidia deliciosa (A. Chev.) 
C. F. Liang \& A. R. Ferguson] (Chalak and Legave, 1997; Pandey et al., 1990).

In Citrus, on the other hand, there is only scant information on parthenogenesis induced by inactivated pollen (Froelicher et al., 2007; Ollitraut et al., 1996). Froelicher et al. (2007) produced five haploid plantlets from three mandarin genotypes by pollinating with pollen of Meyer lemon (C. meyeri Y. Tanaka) irradiated at 150 and 300 Gy of $\gamma$-rays from a cobalt 60 source.

In the present study, we describe in detail the effects of pollination with soft X-ray-irradiated pollen on fruit set and seed development, and demonstrate that pollination with irradiated pollen followed by ovule culture in C.maxima was successful as a means of haploid production.

\section{Materials and Methods}

\section{Plant materials}

'Banpeiyu' pummelo, a monoembryonic diploid cultivar, cultivated at the Fruit Research Institute, Kumamoto Prefectural Agricultural Research Center, Matsubase, Kumamoto, Japan, was used as the seed parent. As pollen parents, 'Fukuhara' sweet orange and 'Tosa-buntan' pummelo, cultivated at the Citrus Experimental Orchard, Faculty of Agriculture, Saga University, were used.

\section{Pollen irradiation}

Collected pollen was placed on paraffin paper in a glass Petri dish $(95 \times 15 \mathrm{~mm})$, which was transferred to a soft X-ray unit (SV-100AW/I; Softex Co. Ltd., Kanagawa, Japan) and irradiated with 0, 200, 400, 600, 800 , and $1000 \mathrm{~Gy}$.

\section{Pollen stainability and in vitro germination of irradiated pollen}

'Fukuhara' sweet orange was used for testing pollen stainability and in vitro germination of irradiated pollen. Pollen stainability was estimated with acetocarmine crushing of nearly mature anthers. In vitro germination of pollen grains was performed on a glass slide covered with a $2 \mathrm{~mm}$ layer of $1 \%(\mathrm{w} / \mathrm{v})$ agar medium containing $10 \%$ sucrose. Five dehisced anthers, each from different flowers, were rubbed on the agar medium, and the slides were then incubated for $10 \mathrm{~h}$ in a moistened chamber at $25^{\circ} \mathrm{C}$ in the dark. For each irradiation dose, pollen stainability and in vitro germination rates were evaluated from three hundred grains with three repetitions.

\section{Effect of pollination with soft X-ray-irradiated pollen on fruit and seed development}

Twenty-five flowers of 'Banpeiyu' pummelo were hand-pollinated with pollen of 'Fukuhara' sweet orange irradiated at each exposure rate, and were immediately covered with paraffin paper bags after emasculation. Fruits were harvested at maturity between November and early January, and fruit sets and weights were recorded. The seeds were extracted from each fruit and classified into three groups, namely developed (normal development), undeveloped (poor growth embryo), and other (empty and ovulelike) seeds. After all developed seeds had been surface-dried and weighed and their seed coats had been removed, they were placed on double layers of moistened filter paper and kept at $25^{\circ} \mathrm{C}$ for seven days. After germination, the seedlings were transplanted into vermiculite in boxes and transferred to a greenhouse. Undeveloped seeds were aseptically cultured on Murashige and Skoog (MS) medium (1962) containing $500 \mathrm{mg} \cdot \mathrm{L}^{-1}$ malt extract, $30 \mathrm{~g} \cdot \mathrm{L}^{-1}$ sucrose, and $2 \mathrm{~g} \cdot \mathrm{L}^{-1}$ gellan gum without the seed coats being removed. These cultures were kept at $25^{\circ} \mathrm{C}$ under continuous illumination $\left(38 \mu \mathrm{mol} \cdot \mathrm{m}^{-2} \cdot \mathrm{s}^{-1}\right)$.

\section{Ovule culture}

Approximately 15 young fruits of 'Banpeiyu' pummelo were collected 10,20, and 40 days after pollination with the $400 \mathrm{~Gy}$-irradiated pollen of 'Fukuhara' sweet orange and 'Tosa-buntan' pummelo. 'Banpeiyu' pummelo fruits pollinated with nonirradiated pollen of 'Fukuhara' sweet orange were used as controls. Ovules were excised aseptically from young fruits with the aid of a dissecting microscope. The ovules were cultured on Murashige and Tucker (MT) medium (1969) containing $500 \mathrm{mg} \cdot \mathrm{L}^{-1}$ malt extract, $20 \mathrm{mg} \cdot \mathrm{L}^{-1}$ adenine, $30 \mathrm{~g} \cdot \mathrm{L}^{-1}$ sucrose, and $2 \mathrm{~g} \cdot \mathrm{L}^{-1}$ gellan gum, and kept at $25^{\circ} \mathrm{C}$ under continuous illumination $\left(38 \mu \mathrm{mol} \cdot \mathrm{m}^{-2} \cdot \mathrm{s}^{-1}\right)$. Callus, embryoid, and plant formation from these ovules was recorded 3 months after culture. Plantlets obtained from the ovule culture were micrografted onto 20-day-old seedlings of trifoliate orange [Poncirus trifoliata (L.) Raf.]. Grafted plantlets were directly transferred to sterilized soil in pots and grown in a greenhouse, which was air-conditioned to maintain a temperature of about $20^{\circ} \mathrm{C}$.

\section{Ploidy level analysis}

Flow cyotometry

Tissue segments were collected from the embryoids or developing leaves of a plantlet, chopped with a razor blade in $2 \mathrm{~mL}$ buffer solution containing $1.0 \%(\mathrm{v} / \mathrm{v})$ Triton X-100, $140 \mathrm{mM}$ mercaptoethanol, $50 \mathrm{mM}$ $\mathrm{Na}_{2} \mathrm{SO}_{3}$, and $50 \mathrm{mM}$ Tris- $\mathrm{HCl}$ at $\mathrm{pH} 7.5$, and incubated for $5 \mathrm{~min}$ according to the preparation method of Yahata et al. (2005a). Crude samples were filtered through Miracloth (Merck KGaA, Darmstadt, Germany) and stained with $25 \mu \mathrm{g} \cdot \mathrm{L}^{-1}$ propidium iodide (PI). The relative fluorescence of total DNA was measured for each nucleus with a Flow Cytometry System (EPICS XL; Beckman Coulter, Fullerton, CA, USA) equipped with an argon laser $(488 \mathrm{~nm}, 15 \mathrm{~mW})$.

\section{Chromosome observation}

Young leaves (approximately 3-5 $\mathrm{mm}$ long) were excised from the plantlet, immersed in $2 \mathrm{mM} 8$ hydroxyquinoline for $6 \mathrm{~h}$ at $4{ }^{\circ} \mathrm{C}$, and fixed in a mixed 
solution of ethanol and acetic acid $(3: 1)$ for $12 \mathrm{~h}$ at $4{ }^{\circ} \mathrm{C}$. Enzymatic maceration and air drying were performed according to the method of Fukui (1996) with some modifications. Young leaves were washed in distilled water to remove the fixative and then macerated in an enzyme mixture containing 2\% (w/v) Cellulase Onozuka RS (Yakult Pharmaceutical Ind. Co. Ltd., Tokyo, Japan), 1\% (w/v) Macerozyme R-200 (Yakult Pharmaceutical Ind. Co. Ltd.), 0.3\% Pectolyase (w/v) (Kyowa Chemical Products Co. Ltd., Osaka, Japan), and $200 \mathrm{mM}$ EDTA at $37^{\circ} \mathrm{C}$ for $40 \mathrm{~min}$. The macerated samples were rinsed with distilled water, and a fixative solution was added. The mixtures were transferred to glass slides. After the slides had been air dried, the chromosomes were stained with 2\% Giemsa solution (Merck KGaA) in 1/30 phosphate buffer $(\mathrm{pH} 6.8)$ for $30 \mathrm{~min}$, rinsed with distilled water, air dried, and observed under an optical microscope.

\section{Origin of haploid}

Total DNA was extracted from young leaves of 'Banpeiyu' pummelo, 'Tosa-buntan' pummelo, and the haploid according to the method of Doyle and Doyle (1987). Total DNA was used for analyses of nuclear DNA by random amplified polymorphic DNA (RAPD) and cleaved amplified polymorphic sequence (CAPS) analysis. RAPD analysis of nuclear DNA was performed by a modified method of Williams et al. (1990). The primers used were OPA20 in Operon random 10-mer primers (Operon Technologies, Inc., Huntsville, AL, USA). CAPS analysis was performed for the internal transcribed spacer (ITS) region in nuclear ribosomal RNA (rRNA). ITS1 and ITS4 were used as primers (Yasui et al., 1998). For each combination of samples and primers, PCR was carried out twice, and only stable polymorphisms were analyzed.

\section{Results and Discussion}

\section{Pollen stainability and in vitro germination}

Non-irradiated pollen of 'Fukuhara' sweet orange had a stainability rate of $82.5 \%$ and an in vitro germination rate of $10.2 \%$, whereas pollen irradiated at doses ranging $200-1000$ Gy showed $78.5-87.6 \%$ stainability and $8.2-$
$11.8 \%$ in vitro germination (Table 1 ). There were no significant differences in stainability and in vitro germination rates among the different doses of soft Xray irradiation. It has been shown that irradiation of pollen hardly affects stainability or in vitro germination in apple (Zhang and Lespinasse, 1991), melon (Sauton and Dumas, 1987), kiwifruit (Musial and Przywara, 1998) and cacao (Theobroma cacao L.) (Falque et al., 1992). In Citrus, Froelicher et al. (2007) reported that in vitro pollen germination of Meyer lemon was not affected at irradiation doses of 0-900 Gy $\gamma$-rays. On the other hand, De Lange and Vincent (1988) reported that in vitro pollen germination of trifoliate orange, pummelo, and sweet lime (C.aurantifolia (Cristm.) Swingle) decreased at irradiation doses above $500 \mathrm{~Gy} \gamma$-rays. The response of pollen to irradiation might depend on the plant genotype and the type of irradiation applied.

\section{Effect of pollination with soft X-ray-irradiated pollen on fruit and seed development}

When pistils of 'Banpeiyu' pummelo were pollinated with pollen of 'Fukuhara' sweet orange irradiated at various doses of soft $\mathrm{X}$-ray exposure, the fruit set and weight differed depending on the amount of radiation (Table 2), i.e., the percentage of fruit set and average fruit weight obtained from flowers pollinated with nonirradiated pollen were $37 \%$ and $1200 \mathrm{~g}$, respectively, whereas those from flowers pollinated with irradiated pollen varied from 20 to $32 \%$ and 894 to $1115 \mathrm{~g}$,

Table 1. Effect of soft X-ray exposure dose on pollen stainability and in vitro germination of 'Fukuhara' sweet orange.

\begin{tabular}{ccc}
\hline \hline $\begin{array}{c}\text { Soft X-ray exposure } \\
\text { dose (Gy) }\end{array}$ & $\begin{array}{c}\text { Stainability } \\
(\%)\end{array}$ & $\begin{array}{c}\text { in vitro germination } \\
(\%)\end{array}$ \\
\hline 0 & 82.5 & 10.2 \\
200 & 87.6 & 11.4 \\
400 & 78.5 & 8.2 \\
600 & 85.6 & 11.8 \\
800 & 82.5 & 10.7 \\
1000 & 84.5 & 10.0 \\
\hline & $\mathrm{NS}^{\mathrm{z}}$ & $\mathrm{NS}$ \\
\hline
\end{tabular}

${ }^{\mathrm{z}}$ Mean separation by Tukey's multiple range test, $P=0.01$.

Table 2. Fruits set, seed contents, and ploidy level of seedlings in the cross of 'Banpeiyu' pummelo with 'Fukuhara' sweet orange pollen irradiated by various doses of soft X-ray exposure.

\begin{tabular}{|c|c|c|c|c|c|c|c|c|c|c|}
\hline \multirow{2}{*}{$\begin{array}{c}\text { X-ray } \\
\text { exposure } \\
\text { dose (Gy) }\end{array}$} & \multirow{2}{*}{$\begin{array}{c}\text { No. of } \\
\text { flowers } \\
\text { pollinated }\end{array}$} & \multirow{2}{*}{$\begin{array}{l}\text { No. of } \\
\text { fruits } \\
\text { set }\end{array}$} & \multirow{2}{*}{$\begin{array}{l}\text { Av. fruit wt. } \\
\text { (g) }\end{array}$} & \multicolumn{2}{|c|}{ No. of seeds per fruit } & \multirow{2}{*}{$\begin{array}{l}\text { No. of seedlings } \\
\text { obtained }\end{array}$} & \multicolumn{4}{|c|}{ No. of seedlings } \\
\hline & & & & Developed & Undeveloped & & $X$ & $2 \mathrm{X}$ & $3 X$ & Unidentified \\
\hline 0 & 30 & $11(36.7 \%)$ & $1200.3 a^{z}$ & 381 & 24 & Not observed & \multicolumn{4}{|c|}{ Not observed } \\
\hline 200 & 25 & $7(28.0 \%)$ & $1115.3 \mathrm{a}$ & 25 & 75 & 22 & 0 & 21 & 0 & 1 \\
\hline 400 & 25 & $8(32.0 \%)$ & $1081.3 \mathrm{a}$ & 6 & 44 & 6 & 0 & 4 & 0 & 2 \\
\hline 600 & 25 & $5(20.0 \%)$ & $893.6 \mathrm{~b}$ & 0 & 8 & 0 & - & - & - & - \\
\hline 800 & 25 & $6(24.0 \%)$ & $926.1 \mathrm{ab}$ & 0 & 0 & 0 & - & - & - & - \\
\hline 1000 & 25 & $5(20.0 \%)$ & $1152.3 \mathrm{a}$ & 0 & 0 & 0 & - & - & - & - \\
\hline
\end{tabular}

\footnotetext{
${ }^{\mathrm{z}}$ Mean separation by Tukey's multiple range test, $P=0.01$.
} 
respectively. The number of seeds per fruit also depended on the exposure dose, tending to decrease with each increase of exposure dose (Fig. 1). Although developed seeds were obtained from 'Banpeiyu' pummelo fruits that underwent 200 and 400 Gy treatments, no developed seed was obtained from treatments over $600 \mathrm{~Gy}$. All seedlings obtained from developed seeds were diploid; no haploid seedlings were obtained in any treatments. Moreover, undeveloped in vitro cultured seeds did not germinate at all.

The effect of pollination with irradiated pollen on fruit set, seed numbers, fruit and seed development has been investigated in many fruit trees, and the irradiation dose has been a factor (De Lange and Vincent, 1988; Froelicher et al., 2007; Pandey et al., 1990). Furthermore, the process of embryo development has been observed by histological analysis in various fruit trees (Musial and Przywara, 1998; Ogata et al., 2008; Peixe et al., 2000; Sniezko and Visser, 1987; Zhang and Lespinasse, 1991). It has been demonstrated that abnormal development of endosperm caused seed abortion in these observations. In the present study, with the increased irradiation dose, the number of developed seeds decreased and undeveloped seeds increased, as in previous studies; however, the developed seeds were all

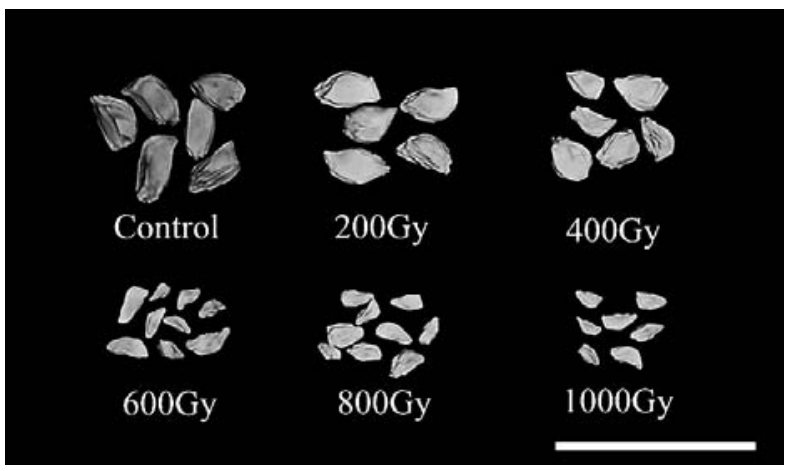

Fig. 1. Seed development in 'Banpeiyu' pummelo crossed with 'Fukuhara' sweet orange pollen irradiated by various doses of soft X-ray exposure $(\mathrm{Bar}=5 \mathrm{~cm})$. diploid, and undeveloped seeds did not germinate. In Citrus, Froelicher et al. (2007) also reported that the number of normal seeds decreased and the number of small seeds increased when three mandarin cultivars, 'Ellendale' tangor, 'Fortune' mandarin, and clementine mandarin, were pollinated with Meyer lemon pollen irradiated at 150 and $300 \mathrm{~Gy}$ of $\gamma$-rays. In the meantime, they succeeded in the induction of five haploid plants from these mandarin cultivars by the culture of small seeds obtained from pollination by irradiated pollen at 150 and $300 \mathrm{~Gy}$. This tendency was observed at doses ranging from 200 to $600 \mathrm{~Gy}$ in the present study, although no haploid was obtained from undeveloped seeds. Presumably, the embryos of many undeveloped seeds obtained in the present study may be considered to have been haploid. In 'Banpeiyu' pummelo, it may be possible to obtain haploid plants using pollen irradiated by soft $\mathrm{X}$-ray at doses ranging from 200 to $600 \mathrm{~Gy}$ combined with ovule culture at an early stage of embryo development.

\section{Ovule culture}

The induction of a haploid plant via ovule culture was carried out because no haploid plants were recovered from seeds following pollination with soft X-rayirradiated pollen. After 3 months of ovule culture, callus formation from the integument was observed (Table 3). When the culture of ovules was initiated 10 days after pollination, the frequency of callus formation was very low, $0.5 \%$ for irradiated pollen of 'Fukuhara' sweet orange and $0.6 \%$ for that of 'Tosa-Buntan' pummelo, whereas callus formation in the culture of ovules initiated 40 days after pollination was $66.3 \%$ for 'Fukuhara' sweet orange and $61.1 \%$ for 'Tosa-Buntan' pummelo. Callus formation depended on the time of ovule culture, and it tended to increase with the progress in time for all treatments. On the other hand, the frequency of embryoid formation was generally very low; a total of eight embryoids was obtained from all treatments (Fig. 2A). The highest frequency $(0.4 \%)$ was obtained when ovule culture was initiated 40 days after pollination with

Table 3. Effect of pollen parents and duration after pollination on the haploid production of 'Banpeiyu' pummelo.

\begin{tabular}{|c|c|c|c|c|c|c|c|}
\hline \multirow{2}{*}{ Pollen parent } & \multirow{2}{*}{$\begin{array}{l}\text { X-ray exposure } \\
\text { dose (Gy) }\end{array}$} & \multirow{2}{*}{$\begin{array}{l}\text { Day after } \\
\text { pollination }\end{array}$} & \multirow{2}{*}{$\begin{array}{l}\text { No. of ovules } \\
\text { cultured }\end{array}$} & \multirow{2}{*}{$\begin{array}{l}\text { No. of ovules } \\
\text { forming callus }\end{array}$} & \multirow{2}{*}{$\begin{array}{l}\text { No. of embryoid } \\
\text { formation }\end{array}$} & \multicolumn{2}{|c|}{ Response } \\
\hline & & & & & & Embryo & Plantlet \\
\hline \multirow{3}{*}{ 'Fukuhara' } & \multirow{3}{*}{0} & 10 & 708 & $7(1.0 \%)$ & $0(0 \%)$ & - & - \\
\hline & & 20 & 845 & $31(3.7 \%)$ & $0(0 \%)$ & - & - \\
\hline & & 40 & 891 & $775(87.0 \%)$ & $1(0.1 \%)$ & 1 & 0 \\
\hline \multirow{3}{*}{ 'Fukuhara' } & \multirow{3}{*}{400} & 10 & 921 & $5(0.5 \%)$ & $3(0.3 \%)$ & $3(2)^{y}$ & 0 \\
\hline & & 20 & 917 & $18(2.0 \%)$ & $0(0 \%)$ & - & - \\
\hline & & 40 & 841 & $558(66.3 \%)$ & $1(0.1 \%)$ & $1(1)$ & 0 \\
\hline \multirow{3}{*}{ 'Tosa-Buntan' } & \multirow{3}{*}{400} & 10 & 879 & $5(0.6 \%)$ & $0(0 \%)$ & - & - \\
\hline & & 20 & 833 & $20(2.4 \%)$ & $0(0 \%)$ & - & - \\
\hline & & 40 & 947 & $579(61.1 \%)$ & $4(0.4 \%)$ & $3(2)$ & $1(1)$ \\
\hline
\end{tabular}

\footnotetext{
${ }^{\mathrm{z}}$ Integument-derived callus.
}

${ }^{\mathrm{y}}$ Values in parentheses show the number of haploids. 
400 Gy-irradiated pollen of 'Tosa-buntan' pummelo. The difference in pollen parents did not significantly affect the frequency of the callus and embryoid formation.

When the embryoids were transferred to plant growth regulator-free MT medium, one plantlet was regenerated from an embryoid in an ovule culture initiated 40 days culture after pollination with $400 \mathrm{~Gy}$-irradiated pollen of 'Tosa-buntan' pummelo (Fig. 2B). In other strains, the embryoids showed enlarged cotyledonary tissue with the development of only an adventitious bud or root (Fig. 2C). Flow cytometric analysis of one regenerated plantlet and five embryoids revealed that they had fluorescence intensity half that of 'Banpeiyu' pummelo (Fig. 3A). Chromosome observation of immature leaflets of the plantlet revealed that it was haploid with 9 chromosomes (Fig. 3B). Furthermore, RAPD and CAPS analysis confirmed DNA amplifications. The haploid was found to have almost the same banding patterns as those of 'Banpeiyu' pummelo, and no unique bands from 'Tosa-buntan' pummelo were formed in the haploid (Figs. 4 and 5). These results indicate that this haploid was of maternal origin. This haploid plantlet was micrografted onto trifoliate orange because it showed a very slow growth rate (Fig. 2D). After grafting, the haploid grew vigorously (Fig. 6); moreover, five haploid embryoids died in culture.

Germanà (2006) demonstrated that the success of this technique is dependent on the choice of the radiation dose, the developmental stage of the embryos at the time of culture, the culture conditions, and the medium requirements. In the present study, ovule culture of 40 days after pollination with irradiated pollen gave the highest frequency of haploid plants and embryoid recovery. Yang (1968) reported that fertilized eggs began to divide 40 to 50 days after pollination in natsudaidai and satsuma mandarin (C. unshiu Marcow.). Ovule
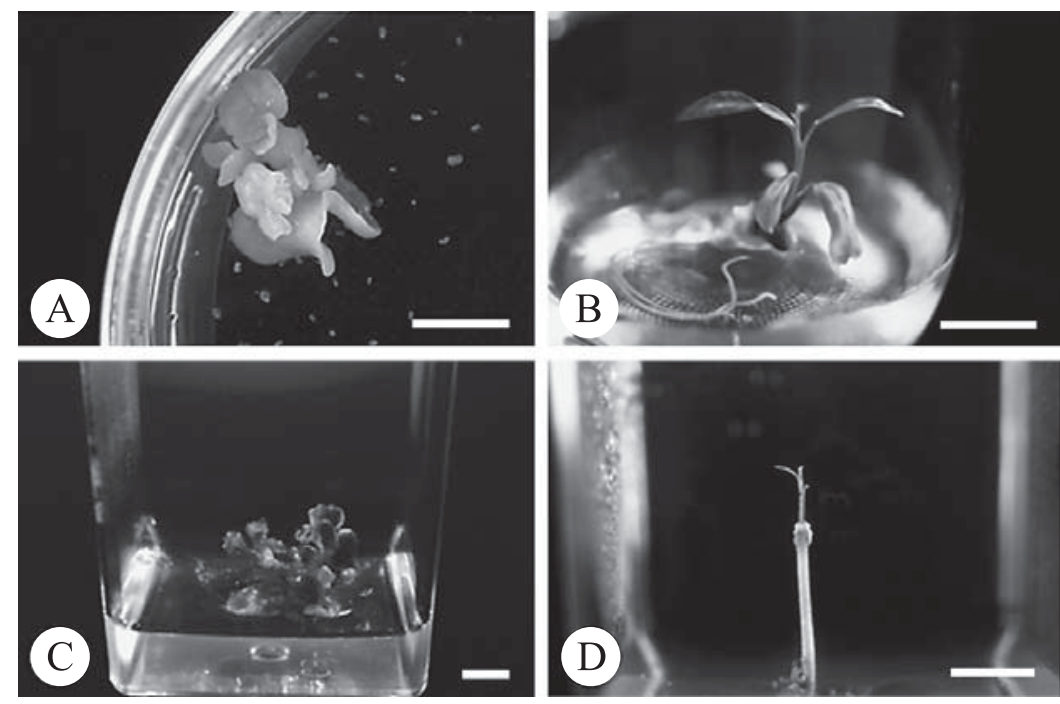

Fig. 2. Ovule culture of 'Banpeiyu' pummelo after pollination with $400 \mathrm{~Gy}$-irradiated pollen of 'Tosa-buntan' pummelo. A: Embryoids, 3 months after culture $(B a r=1 \mathrm{~cm})$. B: A plantlet developed from the embryoid $(B a r=1 \mathrm{~cm})$. C: Abnormal embryoid $(B a r=1 \mathrm{~cm})$. D: 3 weeks after in vitro grafting of the plantlet $(\mathrm{Bar}=1 \mathrm{~cm})$.
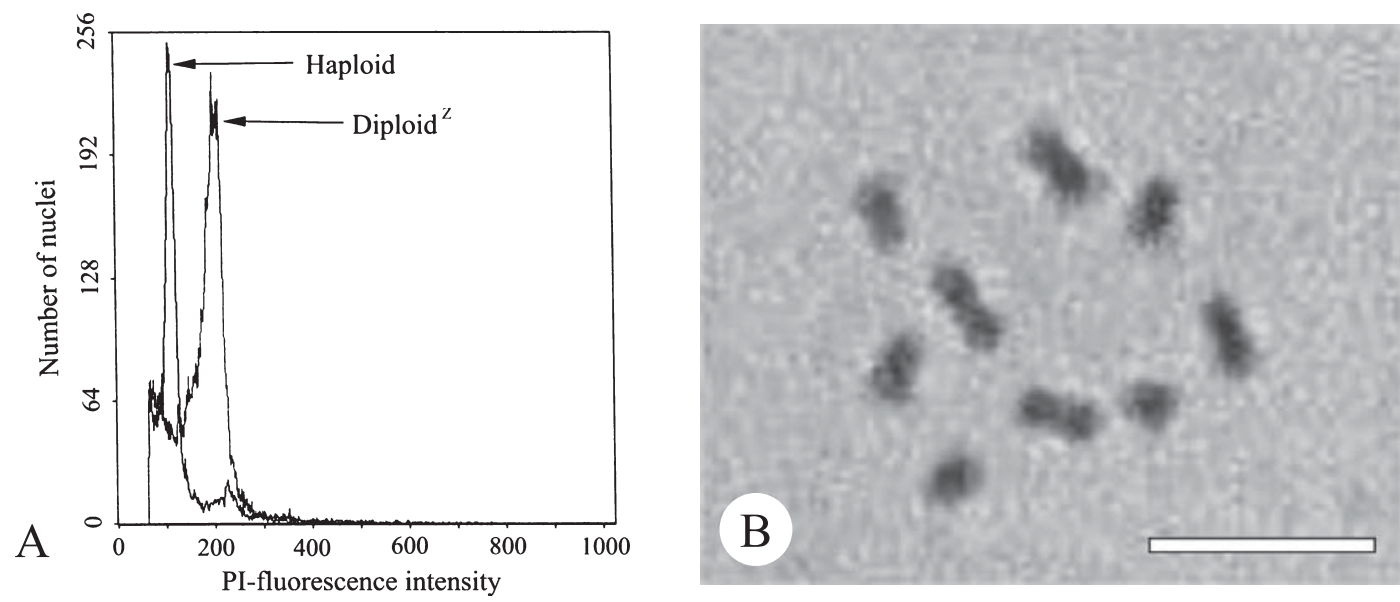

Fig. 3. Flow cytometric analysis and chromosome observation of the plantlet developed from the embryoid of 'Banpeiyu' pummelo. A: Flow cytometric analysis. B: Chromosomes of young leaf cells $(2 \mathrm{n}=\mathrm{X}=9$, Bar $=10 \mu \mathrm{m}) .{ }^{\mathrm{z}}$ 'Banpeiyu' pummelo was used as a control. 


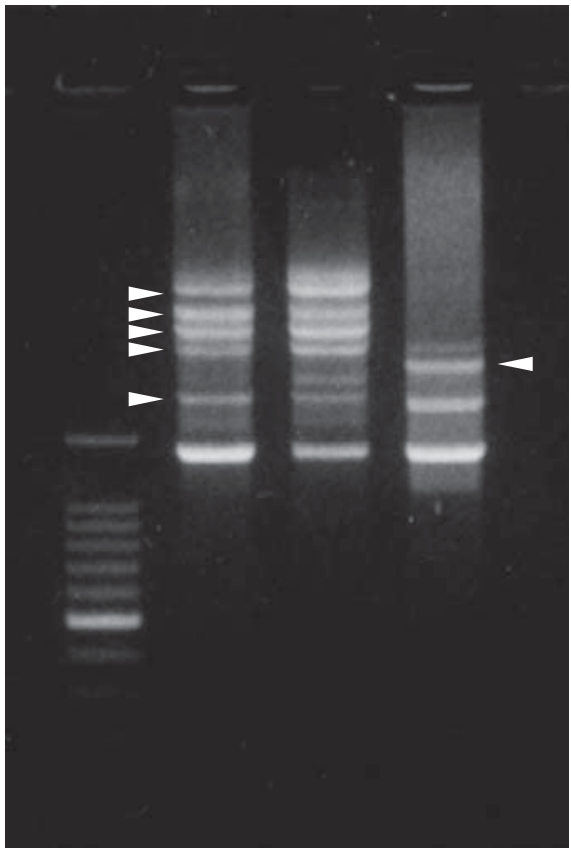

$\begin{array}{llll}\text { M } & \text { B } & \text { H } & \text { T }\end{array}$

Fig. 4. Random amplified polymorphic DNA (RAPD) analysis of 'Banpeiyu' pummelo, the haploid, and 'Tosa-buntan' pummelo. M: 100-bp ladder marker. B: 'Banpeiyu' pummelo. H: Haploid. T: 'Tosa-buntan' pummelo. Arrows indicate bands specific to each parent.

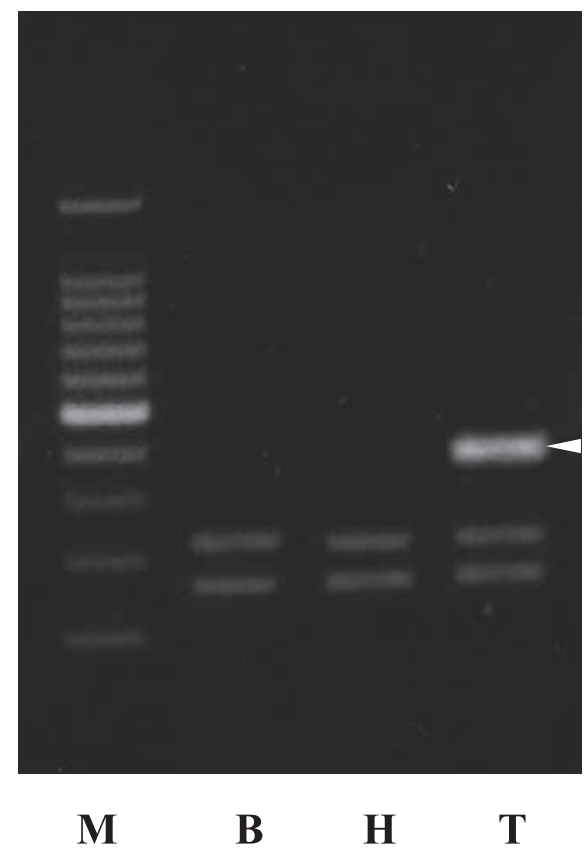

Fig. 5. Restriction pattern of HaeIII-digested ribosomal RNA (rRNA) internal transcribed spacer (ITS) of nuclear genomes. M: 100bp ladder marker. B: 'Banpeiyu' pummelo. H: Haploid. T: 'Tosabuntan' pummelo. Arrows indicate bands specific to each parent.

culture at approximately 40 days after pollination seems to be appropriate for the haploid induction of Citrus. Further study is needed to clarify the optimum conditions

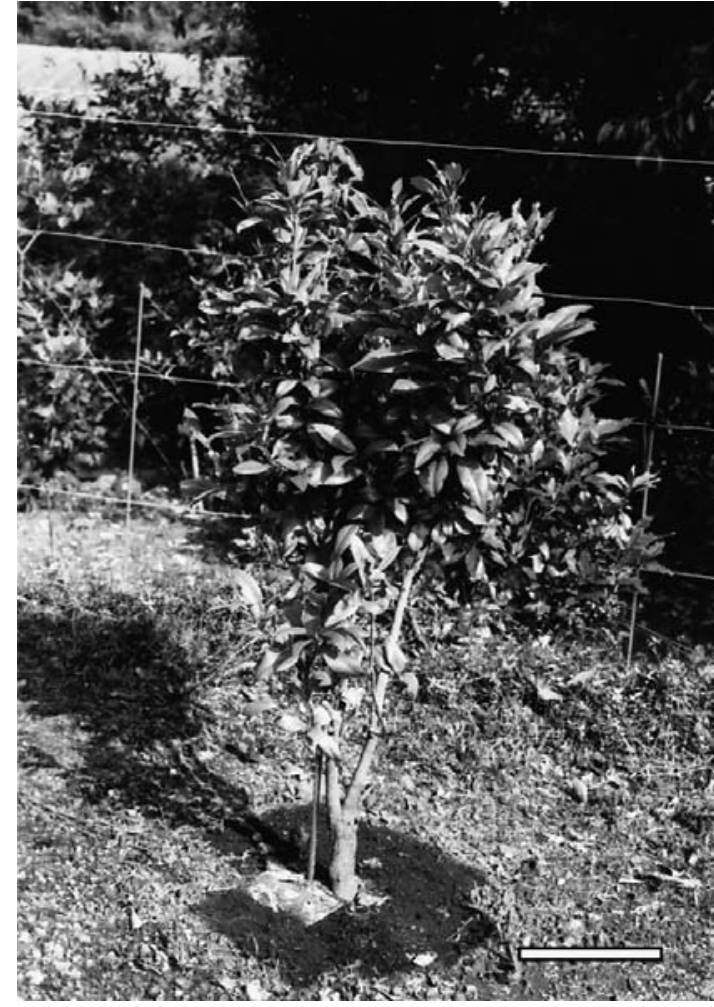

Fig. 6. The haploid plant of 'Banpeiyu' pummelo, 5 years after grafting $(\mathrm{Bar}=20 \mathrm{~cm})$.

of haploid induction, such as selection of the seed and pollen parents, and the culture conditions in the ovule culture of C. maxima (Burm.) Merr.

In Citrus and related genera, haploid production has been reported in natsudaidai, trifoliate orange, clementine mandarin, and 'Lee' (Germanà and Chiancone, 2001, 2003; Germanà et al., 1994; Hidaka et al., 1979; Karasawa, 1971; Oiyama and Kobayashi, 1993). These haploids were very weak, and their growth was slower than that of diploid plants. On the other hand, the haploid of 'Banpeiyu' pummelo produced by Toolapong et al. (1996) showed vigorous growth and flowered for the first time seven years after germination. This haploid plant was confirmed to produce fertile pollen (Yahata et al., 2005a), and several diploid progenies were obtained following the pollination of four diploid plants with pollen from this haploid (Yahata et al., 2005b). The haploid of 'Banpeiyu' pummelo obtained in the present study is expected to produce flowers because it has shown vigorous growth similar to the haploid of 'Banpeiyu' pummelo produced by Toolapong et al. (1996).

In conclusion, we obtained a haploid plant and some haploid embryoids by means of ovule culture in 'Banpeiyu' pummelo. The haploid plant obtained in the present study will be valuable for genetic analysis and possibly for planned breeding, and useful material for triploid seedless breeding by somatic hybridization of haploid and diploid protoplasts. 


\section{Acknowledgements}

The authors are grateful to Dr. Masahiro Mii of the Faculty of Horticulture, Chiba University for his advice and critical reading of this manuscript. The authors thank Mr. Akira Isobe of the Fruit Research Institute, Kumamoto Prefectural Agricultural Research Center, the late Mr. Seiji Yamaguchi of the Citrus Experimental Orchard, Faculty of Agriculture, Saga University, and Mr. Kiyoto Harusaki for kindly providing the experimental materials.

\section{Literature Cited}

Bouvier, L., Y. Z. Zhang and Y. Lespinasse. 1993. Two methods of haploidization in pear, Pyrus communis L.: greenhouse seedling selection and in situ parthenogenesis induced by irradiated pollen. Theor. Appl. Genet. 87: 229-232.

Chalak, L. and J. M. Legave. 1997. Effects of pollination by irradiated pollen in Hayward kiwifruit and spontaneous doubling of induced parthenogenetic trihaploids. Sci. Hortic. 68: 83-93.

De Lange, J. H. and A. P. Vincent. 1988. Studies on Citrus pollination using gamma-irradiated pollen. S. Afr. J. Bot. 54: $257-264$.

Doyle, J. and J. L. Doyle. 1987. A rapid DNA isolation procedure for small quantities fresh leaf tissue. Phytochem. Bul. 19: $11-15$.

Esen, A. and R. K. Soost. 1971. Unexpected triploids in Citrus: The origin identification, and possible use. J. Hered. 62: 329333.

Falque, M., A. A. Kodia, O. Sounigo, A. B. Eskes and A. Charrier. 1992. Gamma-irradiation of cacao (Theobroma cacao L.) pollen: effect on pollen grain viability, germination and mitosis and on fruits set. Euphytica 64: 167-172.

Froelicher, Y., J. Bassene, E. Jedidi-Neji, D. Dambier, R. Morillon1, G. Bernardini, G. Costantino and P. Ollitrault. 2007. Induced parthenogenesis in mandarin for haploid production: induction procedures and genetic analysis of plantlets. Plant Cell Rep. 26: 937-944.

Fukui, K. 1996. Plant chromosome at mitosis, p. 1-17. In: K. Fukui and S. Nakayama (eds.). Plant chromosome. Laboratory methods. CRC Press, Boca Raton, Fla.

Germanà, M. A. 2006. Doubled haploid production in fruit crops. Plant Cell Tissue Organ Cult. 86: 131-146.

Germanà, M. A. and B. Chiancone. 2001. Gynogenetic haploids of Citrus after in vitro pollination with triploid pollen grains. Plant Cell Tissue Organ Cult. 66: 59-66.

Germanà, M. A. and B. Chiancone. 2003. Improvement of Citrus clementina Hort. ex Tan. microspore-derived embryoid induction and regeneration. Plant Cell Rep. 22: 181-187.

Germanà, M. A., Y. Y. Wang, M. G. Barbagallo, G. Iannolino and F. G. Crescimanno. 1994. Recovery of haploid and diploid plantlets from anther culture of Citrus clementina Hort. ex Tan. and Citrus reticulata Blanco. J. Hort. Sci. 69: 473-480.

Grosser, J. W., P. Ollitrault and O. Olivares-Fuster. 2000. Somatic hybridization in citrus: an effective tool to facilitate variety improvement. In Vitro Cell Dev. Biol. 36: 434-449.

Hidaka, T., Y. Yamada and T. Shichijo. 1979. In vitro differentiation of haploid plants by anther culture in Poncirus trifoliata (L.) Raf. Japan. J. Breed. 29: 248-254.

Karasawa, K. 1971. On the occurrence of haploid seedlings in Citrus natsudaidai Hayata. Bul. Sakushingakuin Junior College for Women 1: 1-2.
Katoh, N., M. Hagimori and S. Iwai. 1993. Production of haploid plants of melon by pseudofertilized ovule culture. Plant Tissue Cult. Lett. 10: 60-66.

Murashige, T. and F. Skoog. 1962. A revised medium for rapid growth and bioassays with tobacco tissue cultures. Physiol. Plant. 15: 473-479.

Murashige, T. and D. P. H. Tucker. 1969. Growth factor requirement of citrus tissue culture. p. 1155-1161. In: H. D. Chapmam (ed.). Proc. First Int. Citrus Symp. Vol. 3. University of California, Riverside.

Musial, K. and L. Przywara. 1998. Influence of irradiated pollen on embryo and endosperm development in kiwifruit. Ann. Bot. 82: 747-756.

Ogata, T., T. Takeichi, K. Matsunaga, K. Hasegawa, S. Yamane and K. Sugiyama. 2008. Seed abortion of 'Tosa-Buntan' pummelo pollinated with soft-X-irradiated pollens. Sci. Hortic. 116: 180-185.

Oiyama, I. and S. Kobayashi. 1993. Haploids obtained from diploid $\times$ triploid cross of Citrus. J. Japan. Soc. Hort. Sci. 62: 89-93.

Ollitraut, P., V. Allent and F. Luro. 1996. Production of haploid plants and embryogenic calli of clementine (Citrus reticulata Blanco) after in situ parthenogenesis induced by irradiated pollen. Proc. Intl. Citricult. 2: 913-917.

Pandey, K. K., L. Przywara and P. M. Sanders. 1990. Induced parthenogenesis in kiwifruit (Actinidia deliciosa) through the use of lethally irradiated pollen. Euphytica 51: 1-9.

Peixe, A., M. D. Campos, C. Cavaleiro, J. Barroso and M. S. Pais. 2000. Gamma-irradiated pollen induces the formation of $2 n$ endosperm and abnormal embryo development in European plum (Prunus domestica L., cv. "Rainha Cláudia Verde"). Sci. Hortic. 86: 267-278.

Sauton, A. and V. R. Dumas. 1987. Obtention de plantes haploids chez le melon (Cucumis melo L.) par gynogenese induite par du pollen irradie. Agronomie 7: 141-148.

Sniezko, R. and T. Visser. 1987. Embryo development and fruitset in pear induced by untreated and irradiated pollen. Euphytica 36: 287-294.

Toolapong, P., H. Komatsu and M. Iwamasa. 1996. Triploids and haploid progenies derived from small seeds of 'Banpeiyu' pummelo, crossed with 'Ruby Red' grapefruit. J. Japan. Soc. Hort. Sci. 65: 255-260.

Williams, J. G. K., A. R. Kubelik, K. J. Lival, J. A. Rafalski and S. V. Tingey. 1990. DNA polymorphisms amplified by arbitrary primers are useful as genetic markers. Nucleic Acids Res. 18: 6531-6535.

Yahata, M., S. Harusaki, H. Komatsu, K. Takami, H. Kunitake, T. Yabuya, K. Yamashita and P. Toolapong. 2005a. Morphological characterization and molecular verification of a fertile haploid pummelo (Citrus grandis Osbeck). J. Amer. Soc. Hort. Sci. 130: 34-40.

Yahata, M., H. Kurogi, H. Kunitake, K. Nagano, T. Yabuya, K. Yamashita and H. Komatsu. 2005b. Evaluation of reproduction in a haploid pummelo by crossing with several diploid citrus cultivars. J. Japan. Soc. Hort. Sci. 74: 281-288.

Yang, H. J. 1968. Fertilization and development of embryo on Satsuma orange (Citrus unshiu Marc.) and Natsudaidai (C. natsudaidai Hayata). J. Japan. Soc. Hort. Sci. 37: 102-108.

Yasui, Y. and O. Ohnishi. 1998. Phylogenetic relationships among Fagopyrum species revealed by the nucleotide sequences of the ITS region of the nuclear rRNA gene. Genes Genet. Systems 73: 201-210.

Zhang, Y. X. and Y. Lespinasse. 1991. Pollination with gammairradiated pollen and development of fruits, seeds and parthenogenetic plants in apple. Euphytica 54: 101-109. 